\title{
What Counts Versus What Can Be Counted: The Complex Interplay of Market Orientation and Marketing Performance Measurement
}

Market orientation (MO) and marketing performance measurement (MPM) are two of the most widespread strategic marketing concepts among practitioners. However, some have questioned the benefits of extensive investments in MO and MPM. More importantly, little is known about which combinations of MO and MPM are optimal in ensuring high business performance. To address this research gap, the authors analyze a unique data set of 628 firms with a novel method of configurational analysis: fuzzy-set qualitative comparative analysis. In line with prior research, the authors find that $\mathrm{MO}$ is an important determinant of business performance. However, to reap its benefits, managers need to complement it with appropriate MPM, the level and focus of which vary across firms. For example, whereas large firms and market leaders generally benefit from comprehensive MPM, small firms may benefit from measuring marketing performance only selectively or by focusing on particular dimensions of marketing performance. The study also finds that many of the highest-performing firms do not follow any of the particular best practices identified.

Keywords: organizational configurations, marketing control, market orientation, marketing performance measurement, business performance

Online Supplement. http://dx.doi.org/10.1509/jm.15.0153

"Not everything that can be counted counts, and not everything that counts can be counted."

-William Bruce Cameron

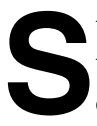
trategic marketing practice and research have generally taken for granted that firms should embrace two organization-wide mechanisms to achieve high business performance: (1) an informal organizational mindset and culture of market orientation (MO; Gebhardt, Carpenter, and Sherry 2006; Narver and Slater 1990) and (2) a formal system

Johanna Frösén is Assistant Professor of Marketing, Graduate School of Management, St. Petersburg State University (e-mail: froesen@gsom.pu.ru). Jukka Luoma is Assistant Professor of Marketing, School of Business, Aalto University (e-mail: jukka.luoma@ aalto.fi). Matti Jaakkola is Assistant Professor of Marketing, Aston Business School, Aston University (e-mail: m.jaakkola@aston. ac.uk). Henrikki Tikkanen is Professor of Marketing, Aalto University School of Business, and Stockholm Business School, Stockholm University (e-mail: henrikki.tikkanen@aalto.fi). Jaakko Aspara is Professor of Marketing, Hanken School of Economics (e-mail: jaakko.aspara@hanken.fi). The authors thank Johanna Frösén's doctoral committee members Professor David Stewart (Loyola Marymount University) and Professor Gopalkrishnan lyer (Florida Atlantic University), Professor Tomas Falk (Aalto University School of Business), and Dr. Mikko Laukkanen (Aalto University Executive Education), as well as the JM review team for their valuable comments on the study. The data for this study were collected as a part of the StratMark research project funded by the Finnish Funding Agency for Technology and Innovation (Tekes). Christian Homburg served as area editor for this article. of marketing performance measurement (MPM; e.g., Rust et al. 2004; Stewart 2009). Indeed, firms almost ritualistically cite MO as one of their core values (e.g., Noble, Sinha, and Kumar 2002). Similarly, in the name of marketing accountability, executives largely consider MPM systems crucial for ensuring that marketing activities enhance business performance (Clark, Abela, and Ambler 2006; CMO Survey 2013; Farris et al. 2006).

More recently, however, researchers and practitioners have questioned the universal benefits of MO and MPM. Kumar et al. (2011) note that although MO is a necessary "cost of competing," it no longer provides a source of superior performance. Some executives of successful firms even question the necessity of MO altogether. For example, Apple's late chief executive officer, Steve Jobs, allegedly did not rely on MO: he did "not market-test anything. It [was] all his own judgment and perfectionism and gut" (Streitfeld 2011). Likewise, comprehensive MPM does not always yield high business performance (Homburg, Artz, and Wieseke 2012; O'Sullivan and Abela 2007). Some of Google's managers, who recently criticized the firm's heavy reliance on MPM data in business development, have echoed this view (see, e.g., Holson 2009; Shankland 2009). Finally, research on control mechanisms in marketing implies that comprehensive, formal MPM may conflict with informal MO (Mintz and Currim 2015; Schepers et al. 2012); therefore, 
a combination of the two may also compromise business performance.

Thus, there is a clear need to better understand how MO and MPM jointly affect business performance in different types of firms and contexts. Yet notwithstanding the aforementioned recent speculations, research that systematically addresses this question is practically nonexistent (for related studies and present research gaps, see Table 1). Consequently, we develop systematic theory and empirical evidence of how executives should combine MO and MPM to attain high business performance. Our research questions are as follows: Which configurations of MO and MPM lead to (1) high and (2) low business performance in different types of firms?

Our findings contribute to the strategic marketing literature in two important ways. First, our study extends the emerging literature examining the interaction effect of MO and MPM on business performance (see Table 1). Specifically, our results provide a more nuanced view of the conditions in which MO might reinforce/reduce the positive effect of comprehensive MPM on business performance (Mintz and Currim 2015): we find that only small market-oriented firms benefit from a selective or focused MPM, whereas large firms and market leaders generally benefit from complementing high MO with comprehensive MPM.

Second, we add important clarity to the ongoing discussion about the universal necessity of MO (Frambach, Fiss, and Ingenbleek 2016; Kumar et al. 2011) or MPM (Homburg, Artz, and Wieseke 2012). Specifically, we (1) further elucidate the role of MO as a necessary but insufficient factor characterizing all configurations that consistently yield high performance; (2) demonstrate that comprehensive MPM is neither a universally necessary nor a sufficient factor for high performance; (3) identify specific conditions under which comprehensive versus selective or focused MPM, combined with high MO, consistently yield high performance; and (4) point out that even for a certain firm type, multiple alternative combinations of MO and MPM are associated with high performance. The following empirical findings highlight our contributions: Whereas (1) MO characterizes all configurations that consistently yield high performance, (2) comprehensive MPM is essential for large but not small firms. (3) Small firms, in general, attain high performance by embracing high MO and focused MPM on some domains but not on others (e.g., concentrating either on customer attitude but not financial metrics or on competitor and financial but not customer attitude metrics), whereas for small market leaders, mere MO may suffice, even without extensive MPM in any domain. These examples further illustrate that (4) across and within individual firm types, there are multiple alternative configurations of MO and MPM that equally effectively yield high performance. In addition, a significant portion of individual high-performing firms $(5.84 \%$ in our sample) exhibit neither high MO nor comprehensive MPM. Likewise, no combination of MO and MPM is consistently associated with low performance. Thus, deviating from the identified best practices (i.e., the aforementioned high-performing configurations) does not necessarily lead to low performance, contrary to the assumptions of earlier configuration theorists (e.g., Vorhies and Morgan 2003).

For managers, these results suggest that although there are high-performing firms that exhibit neither high MO nor comprehensive MPM, firms aiming to achieve high performance consistently (i.e., rather than relying on exceptional practices or luck) will benefit from "matching" a high MO with the appropriate level and content of MPM.

\section{Theoretical Background}

Market orientation is essentially an informal organizational culture, a shared mindset assuming that value creation for customers is the key driver of business profitability (Gebhardt, Carpenter, and Sherry 2006; Narver and Slater 1990). Marketing performance measurement, in turn, represents a formal management tool of setting metrics related to the firm's market performance goals and evaluating performance results relative to these goals (Morgan, Clark, and Gooner 2002; Rust et al. 2004; Stewart 2009). The goals can pertain to different domains of market performance such as customers (e.g., customer satisfaction), competitors (e.g., relative market share gains), and financials (e.g., profit margins). Thus, both MO and MPM serve the same ultimate goal: enhancing the firm's business performance through value creation in the markets (Verhoef and Leeflang 2009).

The theory of marketing control suggests that, in general, informal and formal organizational controls such as MO and MPM may act as mutually supportive drivers for achieving organizational goals (Hult, Ketchen, and Slater 2005; Jaworski, Stathakopoulos, and Krishnan 1993). However, MO and MPM may also interact negatively, as the general theory on organizational control implies (Eisenhardt 1985; Ouchi 1979). Most notably, formal reporting requirements involved in MPM can reduce the time and resources directed at actual MO-aligned behaviors (Mintz and Currim 2015; Schepers et al. 2012).

In support of the notion that the interactions of $\mathrm{MO}$ and MPM may be either positive or negative, configuration theory (e.g., Meyer, Tsui, and Hinings 1993; Vorhies and Morgan 2003) further assumes that the interaction effects of strategic factors depend on how they combine with contextual variables outside of the firm's immediate control. In other words, no positive versus negative interaction effects are expected to hold universally across firms (Ketchen, Thomas, and Snow 1993). In light of this view, the interaction effects of MO and MPM may indeed be positive under some contextual conditions and negative under others.

In the present study, we adopt a set-theoretic approach to organizational configurations (Fiss 2007; Ragin 2000), ${ }^{1}$ putting particular emphasis on (1) the necessity versus

1Woodside $(2010,2013)$ highlights the general potential of such an approach in shedding additional light on complex marketing phenomena, and Ordanini, Parasuraman, and Rubera's (2014) study on service innovation provides an example that realizes some of this potential. 


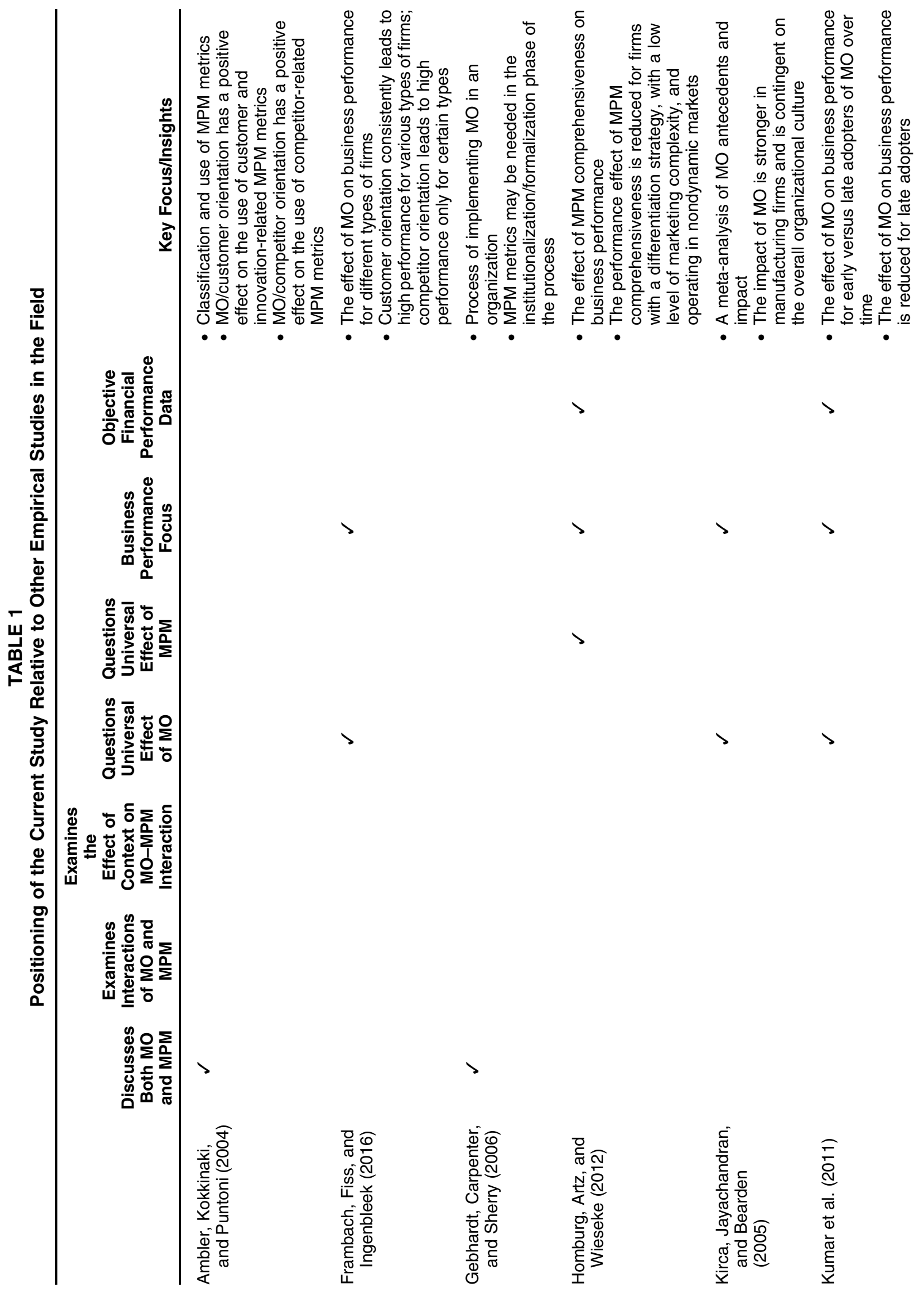




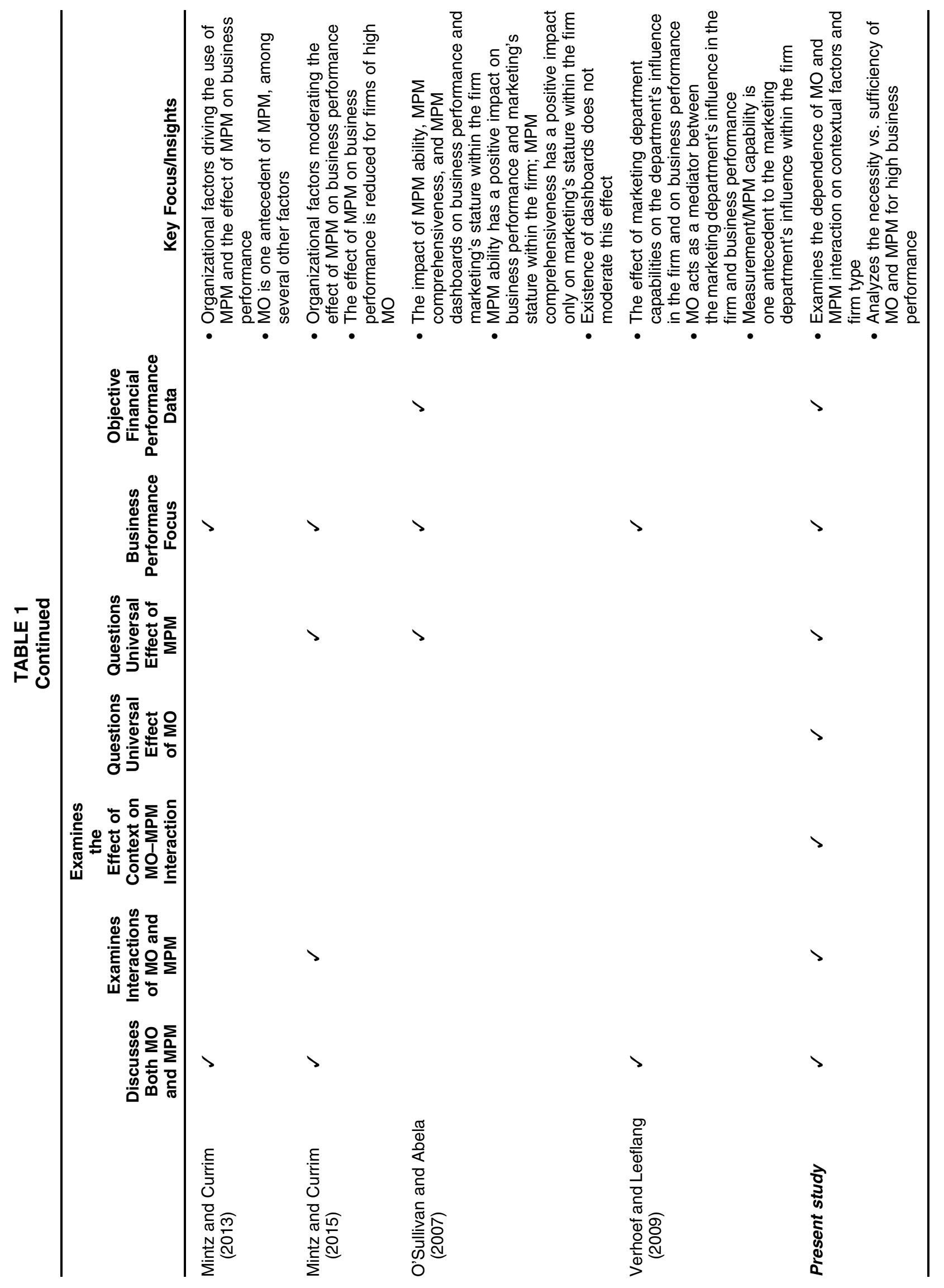


sufficiency of MO and MPM as success factors as well as (2) their equifinality and (3) causal asymmetry. A necessary condition is a factor or combination of factors that characterizes all firms that exhibit the outcome of interest (Ragin 2000). For example, if all firms that reflect high performance also exhibit a high MO and comprehensive MPM, the combination of high MO and comprehensive MPM is a necessary condition for high performance. This is true even if there are also firms that have high MO and comprehensive MPM but do not reflect high performance. Sufficiency, in turn, conceptualizes causation from the opposite perspective. That is, if all firms exhibiting high MO and comprehensive MPM also reflect high performance, the combination of high MO and comprehensive MPM is a sufficient condition for high performance. This is true even if there are also some high-performing firms that do not exhibit high MO or comprehensive MPM. This study focuses on the role of MO and MPM as necessary (but insufficient) parts of configurations that, in turn, are sufficient (but unnecessary) for high performance (Mahoney, Kimball, and Koivu 2009). We operationalize sufficiency of a configuration as consistency, which reflects the proportion of cases exhibiting a certain configuration of factors (e.g., high MO and MPM) that also exhibit the outcome of interest (i.e., high performance).

Equifinality pertains to the existence of multiple configurations that, in parallel, may lead to the same outcome of interest (Doty, Glick, and Huber 1993). That is, even similar firms operating in similar business contexts may reflect multiple alternative configurations of MO and MPM that are consistently associated with high performance. Causal asymmetry, in turn, denotes that whereas a certain configuration may be necessary or sufficient to yield high performance, firms that do not follow this configuration do not necessarily exhibit poor performance (Ragin 2000). This means, for example, that even if high MO combined with comprehensive MPM were a sufficient condition that consistently leads to high performance, low MO combined with no MPM would not necessarily lead to low performance.

\section{Proposition Development}

\section{Necessity of High MO and/or Comprehensive MPM in Different Types of Firms}

Although the overall interaction effect of MO and MPM may be positive or negative, we theorize that the exact form of this interaction depends further on contextual factors, such as the size and market position of the firm (Jaworski 1988; Morgan, Clark, and Gooner 2002). Our central argument is that while some firms benefit from combining high MO with comprehensive MPM, others benefit from selective or focused MPM (i.e., using only a limited number of metrics across different domains of marketing performance or measuring only particular domains extensively).

Firm size. First, regarding firm size, because large firms generally have relatively complex organizations with multiple business units, target markets, product lines, operating locations, and customer-facing employee teams, ${ }^{2}$ they require formalized systems for organization-wide process and outcome controls (Ashby 1956; Jaworski, Stathakopoulos, and Krishnan 1993). Therefore, in large firms, MPM across multiple performance domains is likely to positively complement market-oriented culture in enhancing the complex organization units' performance (Jaworski 1988). In particular, comprehensive MPM may help managers and employees of a large and complex organization to reduce uncertainty (Mintz and Currim 2015) and clarify goals (Gebhardt, Carpenter, and Sherry 2006; Schepers et al. 2012) related to market-oriented behaviors. Thus, we propose:

$\mathrm{P}_{1 \mathrm{a}}$ : For large firms, a combination of high MO and comprehensive MPM (across all domains of customer, competitor, and financial performance) is a necessary part of configurations that consistently yield high business performance.

However, having a less complex organizational "machinery" to track, small firms rarely employ multiple business units, locations, or teams, making the simple customer feedback provided by MO sufficient. Moreover, it is likely that especially in small firms, reporting requirements associated with heavy MPM systems will reduce resources directed at actual market-oriented behaviors of understanding customer needs and providing superior customer service (Schepers et al. 2012), thus thwarting market-oriented employee engagement (see, e.g., Ott 2011). Small organizations are also more likely to suffer from information clutter caused by excessively comprehensive MPM across all performance domains. Therefore, in small firms, MO and MPM are likely to positively complement each other only provided that the use of metrics is not excessively comprehensive (Homburg, Artz, and Wieseke 2012):

$\mathrm{P}_{1 \mathrm{~b}}$ : For small firms, a combination of high $\mathrm{MO}$ and selective MPM (i.e., limited use of customer, competitor, and financial performance metrics) is a necessary part of configurations that consistently yield high business performance.

Market position. Regarding market position, marketoriented firms with different positions may also benefit from different information processes in their marketing (Day and Nedungadi 1994; Greve 1998) and thus need a different focus in the content of their MPM (Jaworski 1988; Mintz and Currim 2013). Because current market leaders have more to lose if the current customer preferences and market conditions change, they are likely to benefit particularly from comprehensive "early warning signal" systems (Srinivasan, Vanhuele, and Pauwels 2010), which would enable them to stay vigilant and constantly up to date about market changes. The beneficial early warning signals to track are likely to relate to customer attitude metrics (e.g., decreasing customer satisfaction), competitor metrics (e.g., competitors' quality improvements), and financial metrics (e.g., eroding profit margins). Following this rationale, we propose the following:

\footnotetext{
${ }^{2}$ We thank an anonymous reviewer for suggesting this point.
} 
$\mathrm{P}_{2 \mathrm{a}}$ : For market leaders, a combination of high $\mathrm{MO}$ and comprehensive MPM (across all domains of customer, competitor, and financial performance) is a necessary part of configurations that consistently yield high business performance.

Market followers, in contrast, are likely to benefit from a more selective approach to MPM, because they do not need to be equally vigilant in all domains of performance. As for small firms, excessive MPM reduces resources directed at concrete market-oriented behaviors of the organization (Schepers et al. 2012), which a market follower firm would need to maintain or improve its customer service and/or competitive position (Narver and Slater 1990). A thorough understanding of customers and competitors, in particular, may help a market-follower firm differentiate its offering (Homburg, Artz, and Wieseke 2012) and survive or improve its competitiveness under intense competition (Jaworski 1988). In addition, because market followers may often follow differentiation or focus strategies rather than the cost leadership strategy (Porter 1980), they are likely to benefit especially from tracking customer and/or competitor metrics, rather than financial metrics. Thus, we propose:

$\mathrm{P}_{2 \mathrm{~b}}$ : For market followers, a combination of high $\mathrm{MO}$ and focused MPM in the domains of customer and/or competitor performance is a necessary part of configurations that consistently yield high business performance.

\section{Sufficiency of Low MO and Noncomprehensive MPM in Certain Individual Firms}

Causal asymmetry suggests that whereas particular configurations of MO and MPM (such as those outlined in $\mathrm{P}_{1}-\mathrm{P}_{2}$ ) may be sufficient for achieving high business performance, firms that do not reflect these configurations do not necessarily experience low performance. In other words, configurations that are consistently associated with low business performance will not necessarily be inverse to those associated with high performance. This also means that although the configurations of MO and MPM outlined in $\mathrm{P}_{1}-\mathrm{P}_{2}$ may consistently yield high business performance, the same outcome may also be attained through other, idiosyncratic strategies. This explains, for example, why firms such as Apple and Google may be able to perform exceptionally well despite their claimed lack of MO or MPM. Indeed, other idiosyncratic drivers, such as exceptional product advantage (Treacy and Wiersema 1997) or lack of competition may explain certain firms' exceptional business performance, irrespective of their partial ignorance of customers or the measurement thereof. Moreover, certain highly successful firms may not be highly market oriented in the sense of attending to or measuring customer preferences but may instead focus on shaping the markets and customer preferences with a more proactive, market-driving approach (Jaworski, Kohli, and Sahay 2000; Sheth 2011). ${ }^{3}$ In summary, we propose:

${ }^{3}$ We thank an anonymous reviewer for suggesting this point.
$\mathrm{P}_{3 \mathrm{a}}:$ A combination of low MO and noncomprehensive MPM is not a sufficient configuration to consistently yield low business performance.

$\mathrm{P}_{3 \mathrm{~b}}$ : Multiple idiosyncratic configurations of high/low MO and comprehensive/noncomprehensive MPM are sufficient to yield high business performance.

\section{Methodology}

\section{Data and Measures}

Data. We collected the data used in the present study in a survey conducted in Finland in 2010 and complemented it with objective performance data. The survey targeted top management in all Finnish firms with more than five employees (using a database from MicroMedia, a commercial service provider) and resulted in a response rate of $10.9 \%$. Considering the respondents' high positions-the most common title being chief executive officer-the response rate is adequate (Fiss 2011; Forlani, Parthasarathy, and Keaveney 2008). Because of the nature of the analysis, which involves identifying all existing combinations of $\mathrm{MO}$ and MPM, we made no imputations of missing data. The analysis excludes responses from micro firms as defined by Statistics Finland (2010; i.e., firms with fewer than ten employees) because of the focus of the study; MO and MPM are considered to play a stronger role in larger firms with more organizational levels and employees to control. We also excluded any observations for which full objective performance data were not available and scrutinized the data to remove any duplicates (in cases of more than one informant per firm, we included the informant with a higher position in the final sample). Finally, we treated firms that displayed a profit margin, return on investment, or return on assets above or below $\pm 100 \%$ as outliers. Following these procedures, our final $\mathrm{n}$ reaches 628 individual firms. A comparison of early and late respondents (i.e., first vs. fourth quartile of respondents) in terms of each of the variables included in the analysis showed no statistically significant differences. Thus, we do not consider nonresponse bias to be a problem (Armstrong and Overton 1977).

The distribution of industries in our sample reflects the overall distribution of firms in the Finnish economy relatively well, with a clear emphasis on business to business ( $71 \%$ of the sample, vs. $27 \%$ focused on business to customer) and industries such as manufacturing; wholesale and retail trade; information and communication; and professional, scientific, and technical activities. The proportion of productfocused $(55 \%)$ and service-focused $(42 \%)$ firms is relatively even, and all firm sizes are well represented (small [49\%], medium-sized [31\%], and large [20\%], compared with $83 \%$, $13 \%$, and $3 \%$, respectively, in the corresponding Finnish population of firms with more than ten employees; Official Statistics of Finland 2010).

Measures. We adopt Narver and Slater's (1990) MKTOR scale to measure MO. For MPM items, we use the taxonomy provided by Ambler, Kokkinaki, and Puntoni (2004) as a basis, with six marketing metrics categories covering the most commonly used MPM metrics. We focus on three of 
these categories: customer attitude metrics, competitor metrics, and financial performance metrics (Petersen et al. 2009). These categories have a close theoretical relation to the MO construct; from a functional perspective, customer attitude metrics aim to generate similar knowledge as a firm's customer orientation, whereas competitor metrics have a similar relationship with competitor orientation. Finally, financial performance forms an essential criterion of MO (Narver and Slater 1990), and to capture the full "chain of marketing productivity" (Rust et al. 2004), nonfinancial metrics need to be linked to financial metrics (Homburg, Artz, and Wieseke 2012).

Rather than constructing a list of all conceivable metrics in each metrics category, we included only the most common metrics in the survey. We assume that whereas a firm may measure customer attitudes, for example, in a variety of ways (some of which are not included in our survey), a firm that measures customer attitudes extensively is also likely to include a large number of commonly used metrics in its selection (included in our survey). Thus, the extent to which the most common metrics in each category are used is treated here as a reflective measure of the managerial focus placed on measuring each performance domain (Ambler, Kokkinaki, and Puntoni 2004). For individual items, see Table 2.

For the analysis, we dummy coded all metrics items ( 1 = focal metric is in use, $0=$ focal metric is not in use), operationalizing the relative use of MPM metrics as the proportion of metrics the firm uses in each of the three categories. We use the number of employees as an indicator of firm size, operationalized using an eight-point survey item $(1=1-5$ employees, $2=6-10$ employees, $3=11-20$ employees, $4=21-50$ employees, $5=51-100$ employees, $6=101-250$ employees, $7=251-500$ employees, and $8=$ $500+$ employees). To measure market position, we asked the respondents to indicate whether they represented market leaders (with the largest market share), challengers (with the second- or third-largest market share), or followers (not in the top three in terms of market share) in their primary markets.

We capture business performance by a firm's profit margin (\%), acquired from a commercial Voitto+ database provided by Suomen Asiakastieto Oy. We used objective performance measures from 2011, together with survey data from 2010, to capture a temporal order indicative of causality (e.g., Hult, Ketchen, and Slater 2005).

\section{Methods of Analysis}

Confirmatory factor analysis. We used confirmatory factor analysis to purify the multi-item construct of MO. After the required eliminations, the data fit the measurement model reasonably well $\left(\chi^{2}=80.90(14), p<.01\right.$; root mean square error of approximation $=.09$; goodness-of-fit index $=.96$; comparative fit index $=.97$; nonnormed fit index $=.95$ ). Composite reliability reached .85 , and the average variance extracted was .46. Sufficiently high factor loadings (the threshold was set to .60) and composite reliability suggest appropriate convergent validity. Taking all these statistics into consideration, our data provide a set of sufficiently robust measures in terms of reliability and validity. Table 3 presents the correlations and sample statistics for all our constructs.

Fuzzy-set qualitative comparative analysis. Fuzzy-set qualitative comparative analysis (fsQCA) is a set-theoretic method for studying organizational configurations using a comparison of cases to differentiate attributes that are related or unrelated to an outcome of interest (Fiss 2011; Ragin 2000). We report the analytical procedure here briefly in the interest of space; the Web Appendix provides further details. The fsQCA procedure involves the identification of cases as configurations that consistently lead to an outcome by using Boolean algebra (for details, see Fiss 2007, 2011). First, the outcome of interest, defined in this study as high business performance, is conceptualized as a set to which each case either does or does not belong. Second, each case is characterized by its degree of membership of each of the conditions and configurations of conditions that explain the outcome-here, MO, MPM, and firm type. Membership of both the outcome and each of the causal conditions vary between full (i.e., 1.00) and zero (i.e., .00) membership (Ragin 2000). These memberships are then collected into a matrix or "truth table" (see the Web Appendix), which distinguishes configurations associated with the outcome of interest from all possible configurations of conditions under study. Next, these configurations are reduced to the most parsimonious, or simple, logical expression that encompasses all the configurations that meet the frequency threshold (number of empirical instances of the configuration) and consistency threshold (which is computed for each configuration). In our analysis, we use the truth table algorithm (Ragin 2008) provided by the fs/QCA 2.5 software package.

Consistency, reported along with the configurations, is an index of sufficiency that determines whether a configuration uniformly leads to the outcome of interest. Coverage represents an index of relevance that indicates the degree to which a configuration is necessary for the outcome to occur. We set the minimum acceptable consistency for configurations at .80 (Fiss 2011) and, due to our relatively large data set, set the minimum frequency to ten empirical instances. We report both "core" and "periphery" conditions for the identified configurations because they provide additional details to the findings. These conditions refer to different causal relationships with the outcome of interest, the core conditions representing conditions identified as most essential for the outcome to occur (with a strong causal link) and periphery conditions representing conditions that are causally weaker and mostly serve to reinforce the features of the core (Fiss 2007; Grandori and Furnari 2008).

Suitability of $f$ s $Q C A$ to our research setting. The causal complexity inherent in configuration theory as well as our set-theoretical assumptions-necessary and sufficient causal conditions, equifinality, and causal asymmetry - can best be addressed using fsQCA (Fiss 2007; Short, Payne, and Ketchen 2008). That is, more established methods, such as linear regression models, clustering algorithms, latent class analysis, and the deviation score approach all come with 


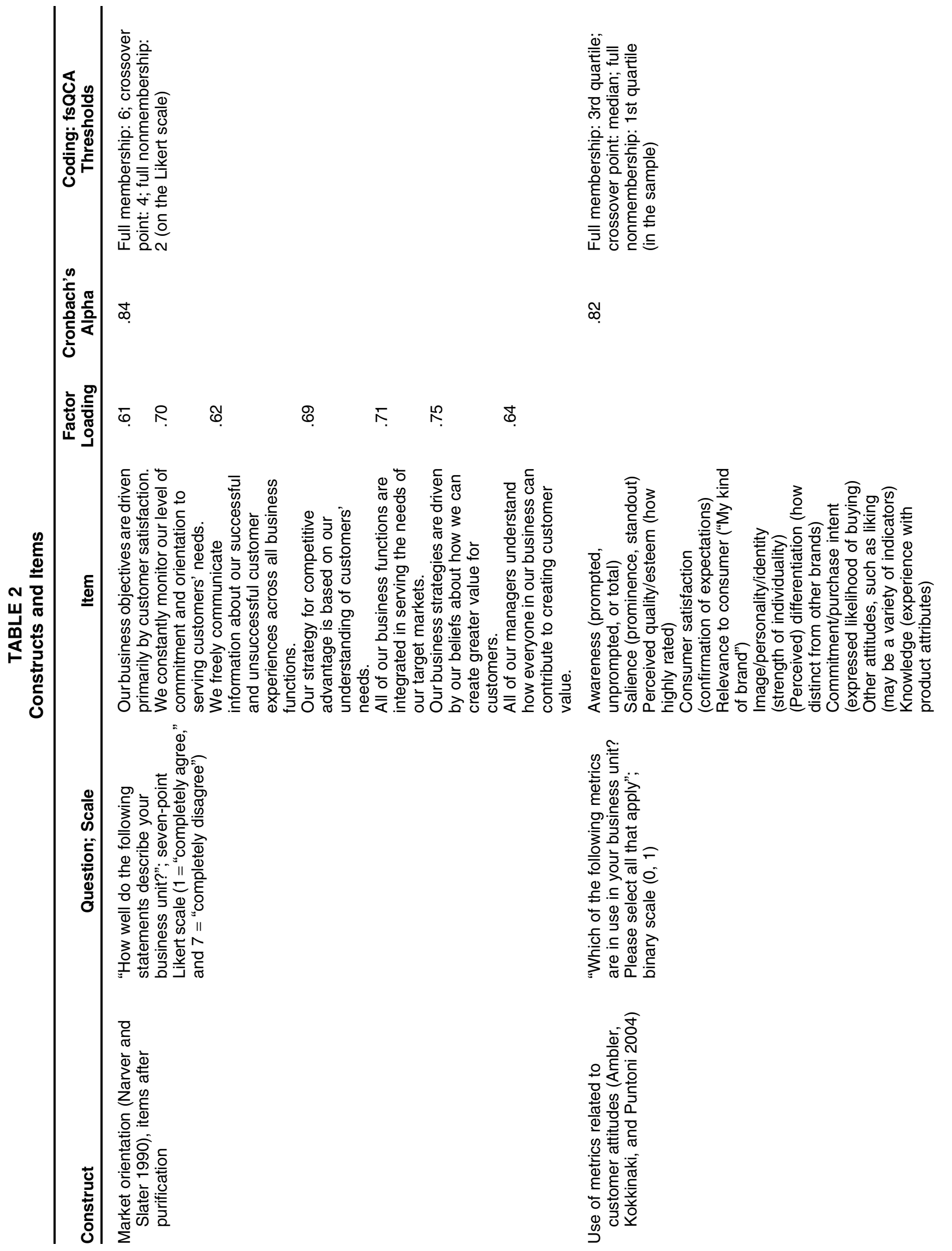




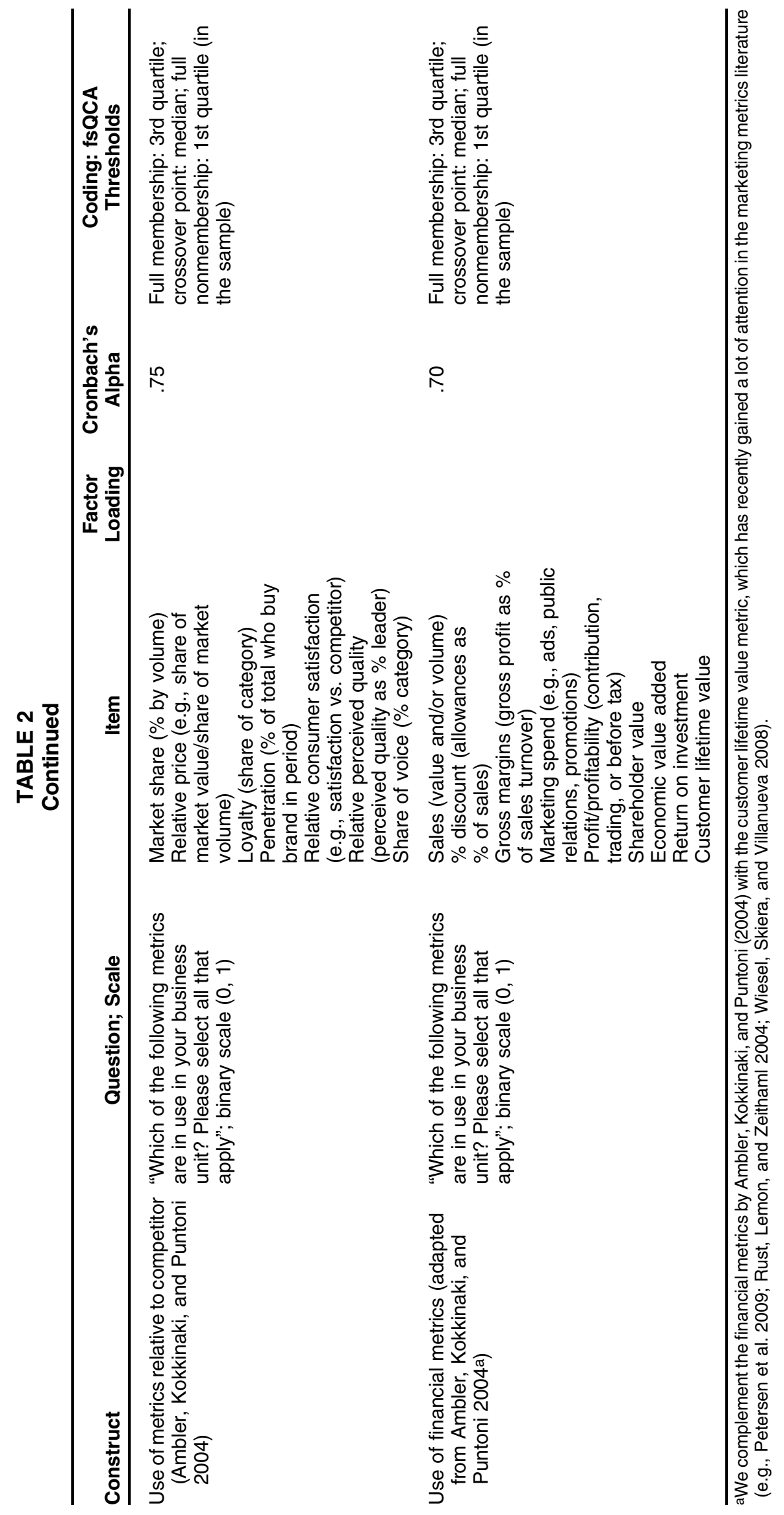


TABLE 3

Descriptive Statistics and Pearson Correlation Coefficients

\begin{tabular}{|c|c|c|c|c|c|c|c|c|c|c|}
\hline Construct & Mean & SD & 1 & 2 & 3 & 4 & 5 & 6 & 7 & 8 \\
\hline 1. Market orientation (1-7) & 5.30 & .89 & 1 & & & & & & & \\
\hline 2. Customer attitude metrics (0-1) & .41 & .29 & $.12^{\star \star \star}$ & 1 & & & & & & \\
\hline 3. Competitor metrics $(0-1)$ & .32 & .28 & $.09^{\star *}$ & $.55^{\star \star \star}$ & 1 & & & & & \\
\hline 4. Financial metrics $(0-1)$ & .49 & .24 & $.07^{\star}$ & $.35^{\star \star \star}$ & $.47^{\star \star \star}$ & 1 & & & & \\
\hline 5. Profit margin $_{\mathrm{t}+1}$ ( $\%$ of turnover) & 4.48 & 13.12 & -.01 & .06 & .02 & -.06 & 1 & & & \\
\hline 6. Turnover (In) & 9.62 & 1.96 & $-.22^{\star \star \star}$ & $.19^{\star \star \star}$ & $.27^{\star \star \star}$ & $.18^{\star \star \star}$ & $.12^{\star \star \star}$ & 1 & & \\
\hline 7. No. of employees (size category, 1-8) & 4.97 & 1.65 & $-.22^{\star \star *}$ & $.18^{\star * *}$ & $.21^{\star \star *}$ & $.13^{\star \star \star}$ & -.01 & $.72^{\star \star \star}$ & 1 & \\
\hline 8. Firm size (large, 1/0) & .20 & .40 & $-.19^{\star \star \star}$ & $.17^{\star \star \star}$ & $.14^{\star \star \star}$ & $.10^{\star \star}$ & .01 & $.57^{\star \star \star}$ & $.81^{\star \star \star}$ & 1 \\
\hline 9. Market position (leader, 1/0) & .31 & .46 & -.00 & $.11^{\star \star \star}$ & $.13^{\star \star \star}$ & .02 & $.07^{\star}$ & $.27^{\star \star \star}$ & $.23^{\star \star \star}$ & $.17^{\star \star \star}$ \\
\hline
\end{tabular}

${ }^{\star} p<.10$.

${ }^{\star *} p<.05$.

${ }^{\star \star \star} p<.01$.

notable limitations (see Table 4). Regression models run into trouble with complex, higher-order interactions that become very difficult to interpret and give rise to multicollinearity issues. Both latent class analysis and cluster analysis would enable us to identify distinct groups of firms that are similar, for example, in type, degree of MO, and use of marketing metrics, and we could use the group membership to predict business performance. However, by using these approaches we would not be able to tell which of the individual configuration elements are necessary (or sufficient) conditions for high performance. Deviation score analysis cannot disentangle the effects of individual conditions either, and it additionally assumes ideal organizational profiles that all firms should follow. Finally, although all the established methods but regression can address equifinality, none of them can accommodate causal asymmetry.

Model specifications for $f_{S} Q C A$. We transformed the outcome and each causal condition into membership scores on the basis of three theoretically driven thresholds of full membership, full nonmembership, and the crossover point representing the point of maximum ambiguity (see Fiss 2011; Ragin 2008, p. 30). For MO, initially measured using Likert scales, we employed the direct method for calibrating fuzzy sets (Ragin 2008, pp. 89-94) based on theoretical anchors (Fiss 2011; Frambach, Fiss, and Ingenbleek 2016; Ordanini, Parasuraman, and Rubera 2014). For metrics use, owing to the lack of external thresholds, we based our calibration on the average use of metrics in each category by the focal firm, with the thresholds based on sample quartiles. We discuss both of these calibrations in more detail in the Web Appendix. We calibrated firm size and market position using crisp set memberships, which can only take values of 0 or 1 . Following Statistics Finland (2010), we defined "large firms" (receiving the value of 1) as firms with more than 250 employees and "small firms" (receiving the value of 0 ) as others. For market position, we distinguished market leaders (1) from challengers or followers (0). Finally, we calibrated the firm's profit margin using $-5 \%, 0 \%$, and $5 \%$ as thresholds for full nonmembership, crossover point, and full membership, respectively. We used the relatively loose thresholds of $\pm 5 \%$ and $0 \%$ because of our research setting; theoretically, we assume effective combinations of MO and MPM to serve as antecedents of high performance, but not necessarily explaining differentials between high-performing versus very high-performing firms (cf. Fiss 2011). Overall, 276 cases (i.e., firms in our data) meet the thresholds of consistency (.80) and frequency (10) (out of the 359 firms associated with high performance; see the Web Appendix), forming the final solution.

Regression analysis. We used ordinary least squares regressions to give additional insights into the nature of the fsQCA findings (Fiss, Sharapov, and Cronqvist 2013).

TABLE 4

Comparison of Different Configurational Analysis Methods

\begin{tabular}{|c|c|c|c|c|c|}
\hline Method & $\begin{array}{l}\text { Complex Interactions } \\
\text { (Causal Complexity) }\end{array}$ & $\begin{array}{l}\text { Impact of Individual } \\
\text { Conditions (Necessity } \\
\text { vs. Sufficiency) }\end{array}$ & Equifinality & $\begin{array}{c}\text { Causal } \\
\text { Asymmetry }\end{array}$ & Approach \\
\hline $\begin{array}{l}\text { Interaction effects } \\
\text { (regression) }\end{array}$ & & $\checkmark$ & & & Confirmatory \\
\hline Cluster analysis & $\checkmark$ & & $\checkmark$ & & Exploratory \\
\hline $\begin{array}{l}\text { Latent class/profile } \\
\text { analysis }\end{array}$ & $\checkmark$ & & $\checkmark$ & & Exploratory \\
\hline $\begin{array}{l}\text { Deviation score } \\
\text { analysis }\end{array}$ & $\checkmark$ & & $\checkmark$ & & Confirmatory \\
\hline fsQCA & $\checkmark$ & $\checkmark$ & $\checkmark$ & $\checkmark$ & Exploratory \\
\hline
\end{tabular}


Configurations identified by the fsQCA were used to predict performance. Specifically, we calculated the membership scores $\mathrm{C}_{\mathrm{ij}}$ of each firm $\mathrm{i}$ with respect to each configuration $\mathrm{j}$ included in the intermediate solution provided by the fsQCA procedure (Fiss 2011). We then used these scores to construct the independent variable of "configuration membership score," which refers to the degree of inclusion of the focal firm in the configuration where its membership score is highest (Jaworski, Stathakopoulos, and Krishnan 1993). Positive and significant regression coefficient provides corroborative evidence that membership in one of the configurations indeed predicts high performance (Vorhies and Morgan 2003).

To control for the possibility that the configurations identified are specific to highly profitable industries, we included industry membership as a control variable. Specifically, we constructed industry dummies using the Statistical Classification of Economic Activities in the European Community section letter codes (equivalent to the Standard Industrial Classification in the United States) and assigned firms in industries with fewer than ten observations in the data (i.e., agriculture, forestry, and fishing; mining and quarrying; electricity, gas, steam, and air conditioning supply; water supply; education; arts, entertainment, and recreaction; and other service activities) to industry category "others" to avoid individual observations distorting our findings. To control for a firm's scale of operations, which might correlate with both the use of metrics and business performance, we used an objective measure of a firm's (logarithmized) turnover from 2010.

\section{Results}

\section{Findings from fsQCA: High-Performing Configurations of MO and MPM}

Table 5 reports four configurations of MPM and MO associated with high business performance, grouped by their core conditions. Configuration $\mathrm{C} 1$ a represents small, marketoriented firms that hold a leading position in their markets; these firms do well, irrespective of MPM. C1b represents market leaders reflecting high MO and comprehensive use of all three types of metrics. Market leadership characterizes both of these configurations as their only core condition. $\mathrm{C} 2$ and $\mathrm{C} 3$ represent small, market-oriented firms with focused MPM. C2 reflects extensive use of customer attitude metrics but limited use of financial metrics (both representing core conditions in the configuration). In contrast, firms in C3 reflect extensive use of financial and competitor metrics but limited use of customer attitude metrics; conditions related to competitor and customer attitude metrics are core conditions of the configuration.

Notably, the solution provides no configurations applicable to large market followers. This might be because of the diversity of the success recipes for such firms; on the one hand, followers generally find themselves in a tougher competitive situation requiring a more explicit focus on competitor-related and financial measurement simply to ensure firm survival (cf. Jaworski 1988). On the other hand, a thorough understanding and measurement of customers and
TABLE 5

Configurations of MO, MPM, and Firm Characteristics Associated with High Performance

\begin{tabular}{|c|c|c|c|c|}
\hline Configuration (Profit Margin \%) & C1a & C1b & $\mathrm{C2}$ & C3 \\
\hline $\begin{array}{l}\text { MO (High) } \\
\text { MPM Metrics }\end{array}$ & $\bullet$ & $\bullet$ & $\bullet$ & - \\
\hline Customer attitude metrics & & • & 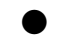 & $\otimes$ \\
\hline Competitor metrics & & • & & ? \\
\hline Financial metrics & & $\bullet$ & $\otimes$ & • \\
\hline \multicolumn{5}{|l|}{ Firm Characteristics } \\
\hline $\begin{array}{l}\text { Firm size (large) } \\
\text { Market position (leader) }\end{array}$ & $\stackrel{8}{0}$ & 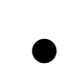 & $\otimes$ & $\otimes$ \\
\hline \multicolumn{5}{|l|}{ Goodness-of-Fit } \\
\hline Raw coverage & .20 & .11 & .18 & .12 \\
\hline Unique coverage & .08 & .04 & .10 & .06 \\
\hline Consistency & .78 & .87 & .84 & .82 \\
\hline Solution coverage & .43 & & & \\
\hline Solution consistency & .81 & & & \\
\hline Frequency cutoff & $10(10)$ & & & \\
\hline Consistency cutoff & $.82(.80)$ & & & \\
\hline
\end{tabular}

Notes: Black circles indicate the presence of a condition, and circles with an " $\times$ " indicate its absence. Large circles indicate core conditions; small circles, peripheral conditions. Blank spaces indicate "don't care."

competitors, in particular, may help a firm differentiate its offering (Homburg, Artz, and Wieseke 2012). Depending on the firm-specific market environment and business strategy, large followers may therefore excel using a variety of combinations of MO and MPM.

Table 5 also provides coverage scores that allow for evaluation of the relative importance of each individual causal configuration. Combined, the four configurations identified account for approximately $43 \%$ of membership in the outcome. This leaves space for other configurations sufficient for high performance in contexts not identified by our analysis due to, for example, not meeting our frequency threshold. Referring to Steve Job's statement-that all of Apple's success was attributable to his own judgment, perfectionism, and gut rather than to an understanding of the customer-whereas all configurations consistently associated with high performance reflect a high MO, there might well be individual firms that excel with different individual recipes. Indeed, it is worthwhile to note that the four highestperforming individual firms in our sample do not belong to any of the aforementioned configurations.

To account for causal asymmetry (e.g., Fiss 2011; Fiss, Sharapov, and Cronqvist 2013), we further searched for configurations consistently associated with low performance. Notably, we identified no such configurations even when repeating the analysis for an extremely loose frequency threshold of 1 . This means that even low MO combined with no MPM does not necessarily lead to low performance (if not to high performance either) perhaps because of the different ways of effectively implementing the marketing concept in diverse markets (e.g., Jaworski, Kohli, and Sahay 2000) or because of other, idiosyncratic drivers of business performance (e.g., Treacy and Wiersema 1997). The lack of low-performing configurations implies that whereas successful firms tend to be 
characterized by certain attributes that fall into a limited number of configurations, a plethora of combinations (not all covered in our findings) exists that may or may not cause low performance when applied to individual firms.

\section{Findings from Post Hoc Analyses: Industry Distribution and Robustness Check}

Table 6 reports the industry distribution of firms belonging to the high-performing configurations. Fisher's exact test (Monte Carlo) shows significant or marginally significant $(p<.05$ or $p<.10)$ deviations of the distribution of industries for configurations C2 $(p=.09 ; .08<p<.10)$ and $\mathrm{C} 3(p=.03 ; .03<$ $p<.04$ ), but not for $\mathrm{C} 1 \mathrm{a}$ or $\mathrm{C} 1 \mathrm{~b}$. That is, whereas $\mathrm{C} 1 \mathrm{a}$ and $\mathrm{C} 1 \mathrm{~b}$ tend to be rather universal in terms of their industry distribution, $\mathrm{C} 2$ and $\mathrm{C} 3$ are more commonly adopted in specific industries. For example, among firms in $\mathrm{C} 2$, the transportation and storage industry is somewhat overrepresented, whereas manufacturing is underrepresented. Among firms in C3, manufacturing is overrepresented, whereas professional, scientific, and technical activities are underrepresented. Thus, C2 seems to be more widely adopted among service industries, and $\mathrm{C} 3$ among product-focused industries.

TABLE 6

Configurations of MO and MPM Associated with High Performance; Industry Distribution

\begin{tabular}{|c|c|c|c|c|c|c|c|}
\hline Industry & C1a & C1b & $\mathbf{C 2}$ & C3 & $\begin{array}{c}\text { Count (\% All } \\
\text { Configurations) }\end{array}$ & $\begin{array}{c}\% \text { Full } \\
\text { Sample }\end{array}$ & $\begin{array}{c}\text { Statistics Finland } \\
\text { (2010; All Finnish } \\
\text { Firms with }>10 \\
\text { Employees) }\end{array}$ \\
\hline $\begin{array}{l}\text { Agriculture, forestry, } \\
\text { and fishing }\end{array}$ & $.00 \%$ & $.00 \%$ & $2.17 \%$ & $.00 \%$ & $(.40 \%)$ & $.16 \%$ & $1.95 \%$ \\
\hline Mining and quarrying & $.79 \%$ & $.00 \%$ & $.00 \%$ & $.00 \%$ & $(.40 \%)$ & $.16 \%$ & $.41 \%$ \\
\hline Manufacturing & $26.77 \%$ & $26.83 \%$ & $15.22 \%$ & $48.48 \%$ & 68 (27.53\%) & $31.37 \%$ & $20.19 \%$ \\
\hline $\begin{array}{l}\text { Electricity, gas, steam, } \\
\text { and air conditioning } \\
\text { supply }\end{array}$ & $1.57 \%$ & $.00 \%$ & $.00 \%$ & $.00 \%$ & $(.81 \%)$ & $.96 \%$ & $.81 \%$ \\
\hline $\begin{array}{l}\text { Water supply; } \\
\text { sewerage, waste } \\
\text { management, and } \\
\text { remediation } \\
\text { activities }\end{array}$ & $.79 \%$ & $.00 \%$ & $.00 \%$ & $.00 \%$ & $(.40 \%)$ & $.32 \%$ & $.75 \%$ \\
\hline Construction & $1.57 \%$ & $.00 \%$ & $2.17 \%$ & $.00 \%$ & $3 \quad(1.21 \%)$ & $2.23 \%$ & $13.97 \%$ \\
\hline $\begin{array}{l}\text { Wholesale and retail } \\
\text { trade; repair of motor } \\
\text { vehicles and } \\
\text { motorcycles }\end{array}$ & $22.05 \%$ & $21.95 \%$ & $19.57 \%$ & $27.27 \%$ & $55(22.27 \%)$ & $18.79 \%$ & $19.48 \%$ \\
\hline $\begin{array}{l}\text { Transportation and } \\
\text { storage }\end{array}$ & $1.57 \%$ & $4.88 \%$ & $8.70 \%$ & $6.06 \%$ & $10 \quad(4.05 \%)$ & $3.34 \%$ & $7.57 \%$ \\
\hline $\begin{array}{l}\text { Accommodation and } \\
\text { food service } \\
\text { activities }\end{array}$ & $1.57 \%$ & $.00 \%$ & $4.35 \%$ & $3.03 \%$ & $5 \quad(2.02 \%)$ & $1.75 \%$ & $4.16 \%$ \\
\hline $\begin{array}{l}\text { Information and } \\
\text { communication }\end{array}$ & $14.96 \%$ & $26.83 \%$ & $17.39 \%$ & $6.06 \%$ & 40 (16.19\%) & $14.33 \%$ & $5.05 \%$ \\
\hline $\begin{array}{l}\text { Financial and } \\
\text { insurance activities }\end{array}$ & $1.57 \%$ & $2.44 \%$ & $2.17 \%$ & $3.03 \%$ & $5 \quad(2.02 \%)$ & $1.91 \%$ & $2.36 \%$ \\
\hline Real estate activities & $3.15 \%$ & $2.44 \%$ & $4.35 \%$ & $6.06 \%$ & $9 \quad(3.64 \%)$ & $2.23 \%$ & $1.61 \%$ \\
\hline $\begin{array}{l}\text { Professional, } \\
\text { scientific, and } \\
\text { technical activities }\end{array}$ & $18.90 \%$ & $9.76 \%$ & $21.74 \%$ & $.00 \%$ & 38 (15.38\%) & $18.31 \%$ & $7.50 \%$ \\
\hline $\begin{array}{l}\text { Administrative and } \\
\text { support service } \\
\text { activities }\end{array}$ & $4.72 \%$ & $4.88 \%$ & $2.17 \%$ & $.00 \%$ & $9 \quad(3.64 \%)$ & $3.50 \%$ & $6.77 \%$ \\
\hline $\begin{array}{l}\text { Public administration } \\
\text { and defense; } \\
\text { compulsory social } \\
\text { security }\end{array}$ & $.00 \%$ & $.00 \%$ & $.00 \%$ & $.00 \%$ & $(.00 \%)$ & $.00 \%$ & $.08 \%$ \\
\hline Education & $.00 \%$ & $.00 \%$ & $.00 \%$ & $.00 \%$ & $(.00 \%)$ & $.16 \%$ & $.62 \%$ \\
\hline $\begin{array}{l}\text { Human health and } \\
\text { social work activities }\end{array}$ & $.00 \%$ & $.00 \%$ & $.00 \%$ & $.00 \%$ & $(.00 \%)$ & $.00 \%$ & $4.56 \%$ \\
\hline $\begin{array}{l}\text { Arts, entertainment, } \\
\text { and recreation }\end{array}$ & $.00 \%$ & $.00 \%$ & $.00 \%$ & $.00 \%$ & $(.00 \%)$ & $.32 \%$ & $1.06 \%$ \\
\hline Other service activities & $.00 \%$ & $.00 \%$ & $.00 \%$ & $.00 \%$ & $0 \quad(.00 \%)$ & $.16 \%$ & $1.11 \%$ \\
\hline Count (\%) & $127(100 \%)$ & $41(100 \%)$ & $46(100 \%)$ & $33(100 \%)$ & $247(100 \%)$ & $628(100 \%)$ & $17,796(100 \%)$ \\
\hline
\end{tabular}


To check for the robustness of our findings, we tested several alternative model specifications. For example, we ran the fsQCA using stricter thresholds for full membership (profit margin $>10 \%$ and $\leq 10 \%$ ). Moreover, to test the sensitivity of our results with respect to the inclusion or exclusion of individual metrics items, we excluded individual metrics at random from the measurement of the MPM constructs and reran the analyses (multiple times). Finally, we performed the configurational analyses by substituting profit margin with return on investment and return on assets as the outcome condition. Not surprisingly, we observed minor changes in the details and number of configurations (Fiss 2011, p. 410). However, the overall pattern of configurations remains similar in all robustness checks: high MO is present in all highperformance configurations; for market leaders (regardless of their size), comprehensive MPM pays off; and small firms benefit from combining high MO with selective or focused MPM (the precise recipe varies). Most importantly, we recalculated the consistency and raw coverages for all of the reported configurations and the overall solution to determine whether the fit between the reported configurations and the data are sensitive to the aforementioned changes in the model assumptions. The indices remained substantially unaffected. Therefore, the ability of our configurational model to explain the data is not sensitive to the assumptions tested.

\section{Findings Relative to Propositions}

The configurations identified in our analysis represent parallel, consistent means for reaching high business performance in diverse organizational contexts. Whereas all configurations reflect a high MO, notable differences in MPM are evident across configurations. It is worthwhile to note that whereas high MO represents a necessary but insufficient part of all highperforming configurations (Ragin 2000), it always remains a peripheral condition (Fiss 2011). This means that even if high MO characterizes all our configurations, individual firms with high performance but low MO may exist. In practice, for example, firms with a significant product advantage (cf. Treacy and Wiersema 1997) might, at least temporarily, perform well without reflecting a high MO. ${ }^{4}$ Notably, in contrast to our findings, Frambach, Fiss, and Ingenbleek (2016) report that in configurations of overall strategic orientations and strategy type, customer orientation appears as a core condition yielding high performance (for the relative role of a market-oriented culture in defining business performance, see also Deshpandé, Farley, and Webster 1993). This implies that whereas in the larger organizational context MO may play a leading role, in the context of marketing control MPM becomes a more dominant determinant of business performance.

Compared with small market leaders, for whom high MO leads to high performance, regardless of the set of marketing metrics the firm uses ( $\mathrm{C} 1 \mathrm{a}$, also partly $\mathrm{C} 2$ and $\mathrm{C} 3$ ), large market leaders perform well only when combining high MO with comprehensive use of customer, competitor, and financial metrics $(\mathrm{C} 1 \mathrm{~b})$. This finding supports $\mathrm{P}_{1 \mathrm{a}}$ and is consistent with the idea that larger firms benefit from MPM more because their

${ }^{4}$ We thank an anonymous reviewer for suggesting this point. organizational structure requires more formal control mechanisms (Jaworski 1988) and because of the economies of scale that help offset the costs related to MPM. In contrast to $\mathrm{P}_{1 \mathrm{~b}}$, however, comprehensive MPM is found to work for smaller market leaders also $(\mathrm{Clb})$.

Compared with $\mathrm{C} 1 \mathrm{~b}$ (and partly compared with $\mathrm{C} 1 \mathrm{a}$ ), the MPM in C2 and C3 is more focused, in support of $\mathrm{P}_{2 \mathrm{a}}$ and $\mathrm{P}_{2 \mathrm{~b}}$. The presence of selected domains of MPM, as well as the absence of others, characterizes both $\mathrm{C} 2$ and $\mathrm{C} 3$. The differences between $\mathrm{C} 2$ and $\mathrm{C} 3$ reflect two alternative strategies of focusing MPM on only customer performance or on a combination of competitor and financial performance. This notion supports $\mathrm{P}_{2 \mathrm{~b}}$; indeed, market followers seem to benefit from more focused MPM compared with the configurations available for market leaders.

Finally, the lack of configurations consistently associated with low performance supports $\mathrm{P}_{3 \mathrm{a}}$. $\mathrm{Cla}$ and $\mathrm{Clb}$, as well as $\mathrm{C} 2$ and C3, represent equifinal paths for similar firms to reach high performance, in support of $\mathrm{P}_{3 \mathrm{~b}}$. Table 7 summarizes our findings.

\section{Regression Findings}

Table 8 presents key findings from our regression analysis, which shed further light on the fsQCA results presented in Table 5. Models 1-3 show that membership in any of the configurations is associated with higher profitability. According to Model 1, an increase in configuration membership from zero to one is associated with an increase in the firm's profit margin by approximately $4 \%(p<.01)$. This result is essentially unaffected by the inclusion of the control variables in the model (see Models 2-3).

However, one should be cautious in interpreting the magnitude of the regression coefficient. Regression analysis assumes that configuration membership is symmetrically associated with performance. That is, the positive effect of being a configuration member is equal to the negative effect of not being a configuration member. A visual inspection of the data, however, suggests that this may not be a plausible assumption (see Figure 1). The data suggest that while belonging to one of the identified configurations enhances performance, not belonging to any of the configurations does not necessarily affect performance negatively. Many firms that do not belong to any of the configurations nevertheless perform well (upper-left corner of Figure 1). These data points cause the regression coefficient between configuration membership and business performance to deflate. At the same time, the scarcity of data points in the lowerright corner of Figure 1 indicates that configuration members seldom perform poorly. Regression analysis misses this causal asymmetry. 5

5In an alternative version of Model 4, we entered all configuration membership scores as separate independent variables. All related coefficients were positive, and the explanatory power of the model increased slightly $\left(\Delta \mathrm{R}^{2}=.002\right)$. However, only the membership score of $\mathrm{C} 2$ was statistically significant. This finding is unsurprising because of the relatively low unique coverages (Ragin 2008, pp. 63-68) of C1 and C3 (Fiss, Sharapov, and Cronqvist 2013). In essence, causal asymmetry causes regression to miss the performance-enhancing capacity of $\mathrm{C} 1$ and $\mathrm{C} 3$. 
TABLE 7

Conclusions Relative to Propositions

\begin{tabular}{|c|c|c|c|}
\hline Proposition Related to ... & Proposition & Theoretical Underpinnings & $\begin{array}{l}\text { Supported/Not Supported } \\
\text { (Relevant Configurations) }\end{array}$ \\
\hline $\begin{array}{l}\text { Necessary but insufficient } \\
\text { conditions (RQ1: Which } \\
\text { configurations of MO and } \\
\text { MPM lead to high business } \\
\text { performance in different } \\
\text { types of firms?) }\end{array}$ & $\begin{array}{l}\mathrm{P}_{1 \mathrm{a}} \text { : For large firms, a } \\
\text { combination of high MO and } \\
\text { comprehensive MPM (across } \\
\text { all domains of customer, } \\
\text { competitor, and financial } \\
\text { performance) is a necessary } \\
\text { part of configurations that } \\
\text { consistently yield high } \\
\text { business performance. } \\
\mathrm{P}_{1 \mathrm{~b}} \text { : For small firms, a } \\
\text { combination of high MO and } \\
\text { selective MPM (i.e., limited use } \\
\text { of customer, competitor, and } \\
\text { financial performance metrics) } \\
\text { is a necessary part of } \\
\text { configurations that consistently } \\
\text { yield high business } \\
\text { performance. } \\
\mathrm{P}_{2 \mathrm{a}} \text { : For market leaders, a } \\
\text { combination of high MO and } \\
\text { comprehensive MPM (across } \\
\text { all domains of customer, } \\
\text { competitor, and financial } \\
\text { performance) is a necessary } \\
\text { part of configurations that } \\
\text { consistently yield high } \\
\text { business performance. } \\
\mathrm{P}_{2 b} \text { : For market followers, a } \\
\text { combination of high MO and } \\
\text { focused MPM in the domains of } \\
\text { customer and/or competitor } \\
\text { performance is a necessary } \\
\text { part of configurations that } \\
\text { consistently yield high } \\
\text { business performance. }\end{array}$ & $\begin{array}{l}\text { Requirement of } \\
\text { comprehensiveness in MPM to } \\
\text { capture the chain-like effects } \\
\text { (Morgan, Clark, and Gooner } \\
\text { 2002; Rust et al. 2004) }\end{array}$ & $\begin{array}{l}\text { Partially supported (supported } \\
\text { by } \mathrm{C} 1 \mathrm{~b} \text {, partially supported } \\
\text { by } \mathrm{C} 1 \mathrm{a} \text { ) }\end{array}$ \\
\hline $\begin{array}{l}\text { Sufficient but unnecessary } \\
\text { configurations (RQ2: Which } \\
\text { configurations of MO and } \\
\text { MPM lead to low business } \\
\text { performance in different } \\
\text { types of firms?) }\end{array}$ & $\begin{array}{l}\mathrm{P}_{3 \mathrm{a}} \text { : A combination of low MO } \\
\text { and noncomprehensive MPM } \\
\text { is not a sufficient configuration } \\
\text { to consistently yield low } \\
\text { business performance. } \\
\mathrm{P}_{3 \mathrm{~b}} \text { : Multiple idiosyncratic } \\
\text { configurations of high/low MO } \\
\text { and comprehensive/ } \\
\text { noncomprehensive MPM are } \\
\text { sufficient to yield high business } \\
\text { performance. }\end{array}$ & $\begin{array}{l}\text { Causal asymmetry in } \\
\text { organizational configurations } \\
\text { (Ragin 2000) } \\
\text { Equifinality in organizational } \\
\text { configurations (Doty, Glick, and } \\
\text { Huber 1993; Ragin 2000) }\end{array}$ & $\begin{array}{l}\text { Supported (lack of low- } \\
\text { performing configurations) } \\
\text { Supported (all configurations) }\end{array}$ \\
\hline
\end{tabular}

Notes: $\mathrm{RQ}=$ research question; $\mathrm{P}=$ proposition; $\mathrm{C}=$ configuration.

The regression analyses reinforce the importance of examining the performance effect of MO and MPM as a configurational rather than as a linear phenomenon. This is because, as Model 4 in Table 8 shows, individually, these constructs do not explain significant proportions of the dependent variable, except for the use of financial performance metrics $(b=-4.66, p<.10$; firm size is also negative and significant: $\mathrm{b}=-1.97, p<.01)$. Moreover, all two-way interactions among the configuration dimension variables (i.e., MO, MPM, firm size, and market position) are statistically insignificant when entered individually $(p>.10)$. When entered simultaneously, only one of 15 possible two-way interactions is significant; namely, the interaction between customer attitude metrics and financial metrics $(b=-20.32, p<.05)$. One statistically significant relationship is not unlikely in such a large number of t-tests.

The fsQCA results partially explain the relatively large $p$-value (.06) associated with the financial performance metrics coefficient. Whereas the absence of extensive use 
TABLE 8

Regression Results (Dependent Variable: Profit Margin $_{t+1}$ )

\begin{tabular}{|c|c|c|c|c|}
\hline \multirow[b]{2}{*}{ Variable } & \multicolumn{3}{|c|}{ Configuration Models } & \multirow{2}{*}{$\frac{\text { Main Effect Model }}{\text { Model } 4}$} \\
\hline & Model 1 & Model 2 & Model 3 & \\
\hline Intercept & $3.10(.74)^{\star \star \star}$ & $2.84(1.03)^{\star * \star}$ & $-7.88(2.91)^{\star \star \star}$ & $-8.79(4.80)^{\star}$ \\
\hline Configuration membership score & $3.66(1.39)^{\star \star \star}$ & $3.52(1.38)^{\star \star}$ & $3.54(1.36)^{\star \star \star}$ & \\
\hline Turnover (In) & & & $1.10(.27)^{\star \star \star}$ & $2.31(.41)^{\star \star \star}$ \\
\hline Market orientation & & & & $.30 \quad(.60)$ \\
\hline Customer attitude metrics & & & & $3.12(2.13)$ \\
\hline Competitor metrics & & & & $.04(2.34)$ \\
\hline Financial performance metrics & & & & $-4.66(2.45)^{\star}$ \\
\hline No. of employees (size category) & & & & $-1.97(.46)^{\star \star \star}$ \\
\hline Market position (leader) & & & & $.67(1.14)$ \\
\hline Industry dummies & No & Yes & Yes & Yes \\
\hline $\mathrm{N}$ & 628 & 628 & 624 & 624 \\
\hline R-square & .01 & .06 & .08 & .10 \\
\hline Adjusted R-square & .01 & .04 & .06 & .08 \\
\hline
\end{tabular}

${ }^{*} p<.10$.

${ }^{\star \star} p<.05$.

${ }^{* * *} p<.01$

Notes: Numbers in parentheses represent standard errors.

of financial performance metrics is associated with high performance in configuration $\mathrm{C} 2$, configurations $\mathrm{C} 1 \mathrm{~b}$ and C3 are characterized by the presence of extensive use of financial performance metrics. That is, the extensive use of financial performance measurement can be associated with both high and low performance, depending on other configuration elements. The assumption of linearity and nonequifinality in regression fails to capture this nuance. In line with this finding, when the data are cleaned from observations belonging to $\mathrm{C} 1 \mathrm{~b}$ and $\mathrm{C} 3$, the effect size and statistical significance of the financial performance metrics coefficient increases $(b=-6.46, p=.02)$.

It is also notable that, according to the regression analyses, MO does not seem to contribute to business performance, contrary to what the extant literature (e.g., Grinstein 2008; Kirca, Jayachandran, and Bearden 2005) and our fsQCA findings suggest. Two observations explain this discrepancy. First, MO is generally high in the sample. When variance in an independent variable is limited in this way, regression analysis often fails to find a significant relationship. Second, according to the fsQCA results, the positive performance effect also depends on other elements in the configuration. As a result, market-oriented firms may perform poorly as well. These findings are consistent with the argument that MO has become a cost of competing in Western societies (Kumar et al. 2011) and is no longer a source of distinctive advantage.

The relatively low $\mathrm{R}^{2}$ in many of our regression models in Table 8 relates partly to the nature of our analyses and the general aims of our study (Fiss 2011). We focused on identifying consistent mechanisms related to MO and MPM that affect business performance, rather than explaining all performance differentials between firms. Another fairly obvious explanation is that our model is relatively parsimonious. Moreover, it is common for cross-industry studies such as ours to reflect lower explanatory power (Homburg, Artz, and Wieseke 2012). Finally, it is noteworthy that the performance measure used is based on firms' objective financial performance (from financial statements) rather than self-reported business performance. This further explains the somewhat lower than usual $\mathrm{R}^{2}$.

\section{Discussion and Conclusions}

\section{Theoretical Contributions}

Our study contributes to the literature on strategic marketing, specifically regarding MO and MPM, in six main respects. First, in terms of the interactions between MO and MPM, we show that MO and MPM can be considered both as complements and substitutes (Eisenhardt 1985; Jaworski 1988) and that the nature of their interaction depends on the organizational context (Mintz and Currim 2015). Second, our study sheds further light on the complex interplay of MO and MPM. On the one hand, our findings reveal two general types of highperforming configurations: universal (equally applicable to all industries) and specific (more commonly adopted in certain industry contexts). On the other hand, many of the highestperforming firms do not belong to any of the configurations but rather represent unique configurations, the outcome of which is highly context specific. This implies that simply copying the practices of best performers may not lead to consistent performance gains (cf. Vorhies and Morgan 2003).

Third, in terms of the individual effects of MO and MPM, our empirical results point to $\mathrm{MO}$ as a necessary but insufficient causal condition consistently present in all configurations associated with high business performance (Garcia-Castro and Francoeur 2014). There are individual high-performing firms, however, that do not belong to any of the configurations and do not display high MO. Indeed, in line with recent research (e.g., Kumar et al. 2011), our findings imply that high MO does not guarantee high performance, but it is difficult (even if not impossible) to achieve high performance without high MO. Fourth, our findings show that comprehensiveness in MPM seems beneficial for large firms (Jaworski 1988), whereas smaller firms benefit from a selective or focused MPM. 
FIGURE 1

Configuration Membership and Business Performance

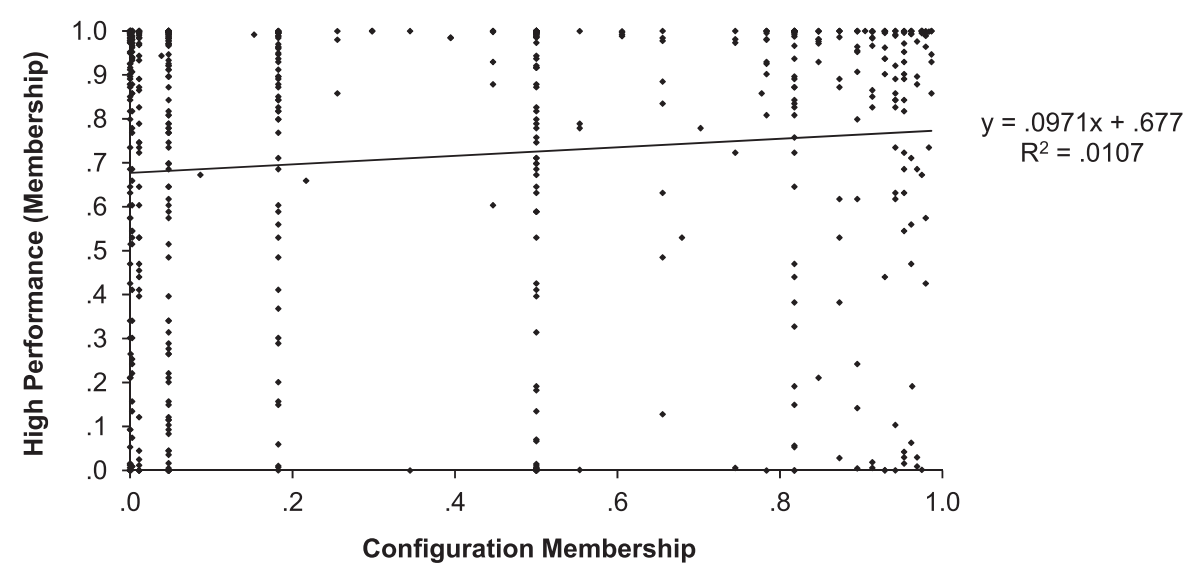

Taken together, our findings challenge and bring more detail to the assumption that, in general, comprehensiveness in MPM is essential for high performance (Ambler, Kokkinaki, and Puntoni 2004; Rust et al. 2004).

Fifth, building on recent findings by Homburg, Artz, and Wieseke (2012), who discuss comprehensiveness from the perspective of overall breadth of measurement, our study sheds further light on the specific content of measurement, especially in terms of three general domains of marketing performancecustomer, competitor, or financial performance. Large market leaders are found to benefit from comprehensive MPM across all three domains, whereas small players may also excel by relying on selective MPM. However, followers require a focused approach to MPM, since excessive MPM that is not aligned with a firm's strategy may distract managerial attention (Day and Nedungadi 1994).

Sixth, in terms of a methodological contribution, building on Vorhies and Morgan's (2003) seminal study, we take configurational studies in strategic marketing an important step further, accounting for the necessity versus sufficiency of specific conditions and their combinations (Fiss 2007), equifinality (Doty, Glick, and Huber 1993), and causal asymmetry (Fiss 2011; Ragin 2000). By comparing the findings of our configurational fsQCA with those of regression analysis, we show how the use of correlational analyses may fail to identify antecedents of performance that still bear managerial relevance. Therefore, fsQCA provides a viable alternative for studying complex strategic marketing phenomena (cf. Vorhies and Morgan 2003).

\section{Managerial Implications}

For managers, our study provides guidelines for carefully matching MO and MPM to their firm-specific business context. First, our findings stress the importance of developing and maintaining a market-oriented organizational culture as a prerequisite for high performance, even if there are rare individual firms excelling without MO in the markets. Second, our configurations, specified by various contextual settings, provide guidelines for firms in complementing MO with appropriate MPM. Specifically, we found selective or focused MPM approaches to work for small firms, whereas larger firms need comprehensive MPM. Notably, for small market leaders, mere MO may suffice, possibly because of simplified organizational structures and an informal flow of information. In such environments, extensive MPM may lead to over-formalizing the market-oriented culture. Thus, MO and MPM are likely to be complementary, provided that the use of metrics is not excessively comprehensive, which might lead to "analysis paralysis" or "metrics madness" (see, e.g., Hempel 2006; McCloskey 2015).

Acknowledging that the ill-specified use of metrics may also obscure the focus in the firm's marketing, our analyses point to a focused MPM as a viable option, especially for small firms; here, the emphasis is on either customer attitude metrics or competitor and financial metrics. It is notable that in addition to focusing on a narrower selection of metrics, not focusing on others is equally characteristic of our high-performing configurations. This finding implies that measuring the wrong things can be costly not only in terms of wasted resources but also in distracting managerial attention.

Third, our study provides two types of benchmarks for developing MO and MPM in different types of firms: more general ones applicable to all firms holding leading positions in their markets, regardless of their industry, and more specific ones that are particularly applicable to certain industry contexts. Configurations $\mathrm{C} 1 \mathrm{a}$ and $\mathrm{C} 1 \mathrm{~b}$, characterized by high MO either combined with comprehensive MPM or not defined by MPM at all, respectively, are equally applicable recipes for high performance across all industries. For small firms that hold a leading position in their markets, mere MO may suffice for high performance, whereas for their larger counterparts, comprehensive MPM is also needed.

Configurations complementing high MO with a focused MPM, in contrast, are industry specific. In our data, C2 (focusing on customer attitude metrics but not financial metrics) is represented mainly by firms in service industries, such as the transportation and storage industry, whereas C3 (focusing on competitor and financial metrics but not customer attitude metrics) is represented mainly by firms in product-focused industries, such as manufacturing. Firms 
such as Dell or Procter \& Gamble may excel because of their superior capability in supply chain management, a capability that can best be supported by closely monitoring the costs and relative margins of each player in the value chain. In contrast, firms such as FedEx or Southwest Airlines, which build their competences on an in-depth understanding of customer needs and value, may benefit more from a customer-centric MPM. Drawing on our findings, the same logic applies to their smaller counterparts and also has further implications for their MPM. The differences in C2 and C3 imply that although the general recipe (i.e., employ MPM in a focused manner) applies to all small firms, regardless of their market position, in practice, the precise recipe may vary, and managers need to take into account the requirements of the industry, as well as firm strategy, in its implementation.

Finally, our study finds no configurations that consistently lead to low business performance. Tolstoy (1877) famously wrote, "Happy families are all alike; every unhappy family is unhappy in its own way"-similarly, it seems that whereas successful firms tend to fall under a limited number of organizational configurations, for nonsuccessful firms the list of potential causal combinations is longer. This finding underlines the usefulness of the successful configurations identified as benchmarks.

\section{Limitations and Further Research}

As with any empirical research, our study is not without limitations. First, as the solution coverage index shows, the configurations presented do not explain all of the variance in performance. This unexplained variance is due partly to the fact that the fsQCA focuses on identifying configurations that consistently lead to an outcome (i.e., high performance) rather than on trying to identify all configurations that might explain the outcome (Fiss 2011). Thus, our configurations of MO and MPM are not exhaustive, and individual firms that do not belong to any of our configurations may reflect high performance as well. However, those firms that reflect combinations of MO and MPM included in our set of configurations consistently reflect high performance. This consistency implies that the configurations identified in this study represent relatively secure benchmarks.

Second, the present study underscores the need to carefully adjust a firm's MO and MPM to the firm- and market-specific context (i.e., in terms of firm size and market position). This is a notion well worth studying further by incorporating more detailed industry- and market-specific factors into the analysis, especially because of the significant potential such analyses hold from the managerial perspective. Because a rather large part of the variance in performance remains unexplained, other conditions not examined in the present study may also contribute to achieving high performance. For example, as we have already noted in the context of MPM focus and content, a firm building its competitive advantage on cost leadership may benefit from a focus on financial performance, whereas a firm adopting a differentiation strategy may benefit from a focus on customer and competitor performance, and a firm focusing on serving niche markets may benefit from a focus on customer performance (e.g., Porter 1980). Further research should empirically address the impact of strategy type on the interplay of MO and MPM.

Finally, because the fsQCA concentrates on configurations found in the data and the data set employed concentrates on a national sample of Finnish companies only, our results should be generalized to any other contexts with caution. For example, in the context of nascent markets, the very essence of marketing performance, as well as the role of MO, might significantly differ from the Finnish setting (Sheth 2011), potentially leading to significantly different success recipes. To gain a more comprehensive view of the successful configurations in specific market contexts, the present study should be replicated in different geographical markets. However, we believe that at a more general level, our findings related to the overall role of MO and MPM in large versus small firms and market leaders versus followers apply across different contexts, even if the exact success recipes may vary. Because the landscape of MPM is constantly changing with big data, electronic commerce, and overall digitalization of businesses bringing new, more affordable tools for MPM to the markets (Kumar 2015), longitudinal studies of the use, role, and performance implications of MPM are also encouraged.

\section{Conclusion}

In this study, we have addressed how combinations of MO and MPM lead to high business performance. "Not everything that counts can be counted"-therefore, a marketoriented organizational culture is needed to tap into the tacit, fuzzy aspects of markets. However, MO is seldom a sufficient condition for high performance; in most organizations, MO yields high performance only when complemented by relevant MPM-either (1) comprehensive (in large and/or market-leading firms) or (2) selective or focused (in small firms). Thus, although this study reaffirms the benefits of comprehensive MPM for some firms, for others, selective or focused MPM is the superior choice because "not everything that can be counted counts."

\section{REFERENCES}

Ambler, Tim, Flora Kokkinaki, and Stefano Puntoni (2004), "Assessing Marketing Performance: Reasons for Metrics Selection," Journal of Marketing Management, 20 (3/4), 475-98.

Armstrong, J. Scott and Terry S. Overton (1977), "Estimating Non-Response Bias in Mail Surveys," Journal of Marketing Research, 14 (August), 396-402.

Ashby, W. Ross (1956), An Introduction to Cybernetics. New York: John Wiley \& Sons.

Clark, Bruce H., Andrew V. Abela, and Tim Ambler (2006), "Behind the Wheel," Marketing Management, 15 (3), 19-23.

CMO Survey (2013), "In Search of Marketing Excellence: Ten Differences Between High-Performing and Low-Performing Companies," (January 16), (accessed February 25, 2016), [available at http://cmosurvey.org/blog/in-search-of-marketingexcellence-ten-differences-between-high-performing-and-lowperforming-companies/]. 
Day, George S. and Prakash Nedungadi (1994), "Managerial Representations of Competitive Advantage," Journal of Marketing, 58 (April), 31-44.

Deshpandé, Rohit, John U. Farley, and Frederick E. Webster Jr. (1993), "Corporate Culture, Customer Orientation, and Innovation in Japanese Firms: A Quadrad Analysis," Journal of Marketing, 57 (January), 23-37.

Doty, D. Harold, William H. Glick, and George P. Huber (1993), "Fit, Equifinality, and Organizational Effectiveness: A Test of Two Configurational Theories," Academy of Management Journal, 36 (6), 1196-250.

Eisenhardt, Kathleen M. (1985), "Control: Organizational and Economic Approaches," Management Science, 31 (2), 134-49.

Farris, Paul W., Neil T. Bendle, Phillip E. Pfeifer, and David J. Reibstein (2006), Marketing Metrics: 50+ Metrics Every Executive Should Master, 3rd ed. Upper Saddle River, NJ: Wharton School Publishing.

Fiss, Peer C. (2007), "A Set-Theoretic Approach to Organizational Configurations," Academy of Management Review, 32 (4), 1180-98. (2011), "Building Better Causal Theories: A Fuzzy Set Approach to Typologies in Organization Research," Academy of Management Journal, 54 (2), 393-420.

, Dmitry Sharapov, and Lasse Cronqvist (2013), "Opposites Attract? Opportunities and Challenges for Integrating Large-N QCA and Econometric Analysis," Political Research Quarterly, 66 (1), 191-98.

Forlani, David, Madhavan Parthasarathy, and Susan M. Keaveney (2008), "Managerial Risk Perceptions of International EntryMode Strategies: The Interaction Effect of Control and Capability," International Marketing Review, 25 (3), 292-311.

Frambach, Ruud T., Peer C. Fiss, and Paul T.M. Ingenbleek (2016), "How Important is Customer Orientation for Firm Performance? A Fuzzy Set Analysis of Orientations, Strategies, and Environments," Journal of Business Research, 69 (4), 1428-36.

Garcia-Castro, Roberto and Claude Francoeur (2014), "When More Is Not Better: Complementarities, Costs and Contingencies in Stakeholder Management," Strategic Management Journal, 37 (2), 406-24.

Gebhardt, Gary F., Gregory S. Carpenter, and John F. Sherry Jr. (2006), "Creating a Market Orientation: A Longitudinal, Multifirm, Grounded Analysis of Cultural Transformation," Journal of Marketing, 70 (October), 37-55.

Grandori, Anna and Santi Furnari (2008), "A Chemistry of Organization: Combinatory Analysis and Design," Organization Studies, 29 (3), 459-85.

Greve, Henrich R. (1998), "Managerial Cognition and the Mimetic Adoption of Market Positions: What You See Is What You Do," Strategic Management Journal, 19 (10), 967-88.

Grinstein, Amir (2008), "The Effect of Market Orientation and Its Components on Innovation Consequences: A Meta-Analysis," Journal of the Academy of Marketing Science, 36 (2), 166-73.

Hempel, Jessi (2006), "Metrics Madness," Bloomberg, (accessed December 3, 2015), [available at http://www.bloomberg.com/ bw/stories/2006-09-24/metrics-madness].

Holson, Laura M. (2009), "Putting a Bolder Face on Google," New York Times, (February 28), (accessed February 25, 2016), [available at http://www.nytimes.com/2009/03/01/business/01marissa. html].

Homburg, Christian, Martin Artz, and Jan Wieseke (2012), "Marketing Performance Measurement Systems: Does Comprehensiveness Really Improve Performance?" Journal of Marketing, 76 (May), 56-77.

Hult, G. Tomas M., David J. Ketchen, and Stanley F. Slater (2005), "Market Orientation and Performance: An Integration of
Disparate Approaches," Strategic Management Journal, 26 (12), $1173-81$.

Jaworski, Bernard J. (1988), "Toward a Theory of Marketing Control: Environmental Context, Control Types, and Consequences," Journal of Marketing, 52 (July), 23-39.

_ Ajay K. Kohli, and Arvind Sahay (2000), "Market-Driven Versus Driving Markets," Journal of the Academy of Marketing Science, 28 (1), 45-54.

, Vlasis Stathakopoulos, and H. Shanker Krishnan (1993), "Control Combinations in Marketing: Conceptual Framework and Empirical Evidence," Journal of Marketing, 57 (January), 57-69.

Ketchen, David J., Jr., James B. Thomas, and Charles C. Snow (1993), "Organizational Configurations and Performance: A Comparison of Theoretical Approaches," Academy of Management Journal, 36 (6), 1278-313.

Kirca, Ahmet H., Satish Jayachandran, and William O. Bearden (2005), "Market Orientation: A Meta-Analytic Review and Assessment of its Antecedents and Impact on Performance," Journal of Marketing, 69 (April), 24-41.

Kumar, V. (2015), "Evolution of Marketing as a Discipline: What Has Happened and What to Look Out For," Journal of Marketing, 79 (January), 1-9.

- Eli Jones, Rajkumar Venkatesan, and Robert P. Leone (2011), "Is Market Orientation a Source of Sustainable Competitive Advantage or Simply the Cost of Competing?" Journal of Marketing, 75 (January), 16-30.

Mahoney, James, Erin Kimball, and Kendra L. Koivu (2009), "The Logic of Historical Explanation in the Social Sciences," Comparative Political Studies, 42 (1), 114-46.

McCloskey, Heather (2015), "Focus on the Metrics that Matter: Identifying Your Product's Key Metrics and KPIs," (accessed December 3, 2015), [available at https://community.uservoice. com/blog/product-development-metrics/]

Meyer, Alan D., Anne S. Tsui, and C.R. Hinings (1993), "Configurational Approaches to Organizational Analysis," Academy of Management Journal, 36 (6), 1175-95.

Mintz, Ofer and Imran S. Currim (2013), "What Drives Managerial Use of Marketing and Financial Metrics and Does Metric Use Affect Performance of Marketing-Mix Activities?" Journal of Marketing, 77 (March), 17-40.

and - (2015), "When Does Metric Use Matter Less? How Firm and Managerial Characteristics Moderate the Relationship Between Metric Use and Marketing Mix Performance," European Journal of Marketing, 49 (11/12), 1809-56.

Morgan, Neil A., Bruce H. Clark, and Rich Gooner (2002), "Marketing Productivity, Marketing Audits, and Systems for Marketing Performance Assessment: Integrating Multiple Perspectives," Journal of Business Research, 55 (5), 363-75.

Narver, John C. and Stanley F. Slater (1990), "The Effect of a Market Orientation on Business Profitability," Journal of Marketing, 54 (October), 20-35.

Noble, Charles H., Rajiv K. Sinha, and Ajith Kumar (2002), "Market Orientation and Alternative Strategic Orientations: A Longitudinal Assessment of Performance Implications," Journal of Marketing, 66 (October), 25-39.

Official Statistics of Finland (2010), "Finnish Enterprises," (accessed December 3, 2015), [available at http://pxnet2.stat.fi/PXWeb/sq/ beec95f3-dc4a-47e8-8489-6000ec8c4cb0; http://pxnet2.stat.fi/ PXWeb/sq/ac096988-55f2-41d3-a9f0-f27157852af5].

Ordanini, Andrea, A. Parasuraman, and Gaia Rubera (2014), "When the Recipe is More Important Than the Ingredients: A Qualitative Comparative Analysis (QCA) of Service Innovation Configurations," Journal of Service Research, 17 (2), 134-49. 
O'Sullivan, Don and Andrew V. Abela (2007), "Marketing Performance Measurement Ability and Business Performance," Journal of Marketing, 71 (April), 79-93.

Ott, Adrian C. (2011), "Are Scorecards and Metrics Killing Employee Engagement?" Harvard Business Review, (July 12), (accessed December 3, 2015), [available at https://hbr.org/2011/ 07/are-scorecards-and-metrics-kil].

Ouchi, William G. (1979), "A Conceptual Framework for the Design of Organizational Control Mechanisms," Management Science, 25 (9), 833-48.

Petersen, Andrew J., Leigh McAlister, David J. Reibstein, Russell S. Winer, V. Kumar, and Geoff Atkinson (2009), "Choosing the Right Metrics to Maximize Profitability and Shareholder Value," Journal of Retailing, 85 (1), 95-111.

Porter, Michael E. (1980), Competitive Strategy: Techniques for Analyzing Industries and Competitors. New York: The Free Press.

Ragin, Charles C. (2000), Fuzzy Set Social Science. Chicago: University of Chicago Press.

(2008), Redesigning Social Inquiry: Fuzzy Sets and Beyond. Chicago: University of Chicago Press.

Rust, Roland T., Tim Ambler, Gregory S. Carpenter, V. Kumar, and Rajendra K. Srivastava (2004), "Measuring Marketing Productivity: Current Knowledge and Future Directions," Journal of Marketing, 68 (October), 76-89.

, Katherine N. Lemon, and Valarie A. Zeithaml (2004), "Return on Marketing: Using Customer Equity to Focus Marketing Strategy," Journal of Marketing, 68 (1), 109-27.

Schepers, Jeroen, Tomas Falk, Ko de Ruyter, Ad de Jong, and Maik Hammerschmidt (2012), "Principles and Principals: Do Customer Stewardship and Agency Control Compete or Complement When Shaping Frontline Employee Behavior?" Journal of Marketing, 76 (November), 1-20.

Shankland, Stephen (2009), "Google Designer Leaves, Blaming Data-Centrism," CNet.com, (March 20), (accessed February 25, 2016), [available at http://www.cnet.com/news/google-designerleaves-blaming-data-centrism/].

Sheth, Jagdish N. (2011), "Impact of Emerging Markets on Marketing: Rethinking Existing Perspectives and Practices," Journal of Marketing, 75 (July), 166-82.
Short, Jeremy C., G. Tyge Payne, and David J. Ketchen (2008), "Research on Organizational Configurations: Past Accomplishments and Future Challenges," Journal of Management, 34 (6), 1053-79.

Srinivasan, Shuba, Marc Vanhuele, and Koen Pauwels (2010), "Mind-Set Metrics in Market Response Models: An Integrative Approach," Journal of Marketing Research, 47 (August), $672-84$.

Statistics Finland (2010), "Concepts and Definitions: Micro Enterprise," (accessed December 3, 2015), [available at http://www. stat.fi/meta/kas/mikroyritys_en.html].

Stewart, David W. (2009), "Marketing Accountability: Linking Marketing Actions to Financial Results," Journal of Business Research, 62 (6), 636-43.

Streitfeld, David (2011), "Jobs Steps Down at Apple, Saying He Can't Meet Duties," New York Times, (August 24), (accessed February 25, 2016), [available at http://www.nytimes.com/2011/ 08/25/technology/jobs-stepping-down-as-chief-of-apple.html].

Tolstoy, Leo (1877), Anna Karenina. Moscow: The Russian Messenger.

Treacy, Michael and Fred Wiersema (1997), The Discipline of Market Leaders: Choose Your Customers, Narrow Your Focus, Dominate Your Market. New York: Perseus Publishing.

Verhoef, Peter C. and Peter S. H. Leeflang (2009), "Understanding the Marketing Department's Influence Within the Firm," Journal of Marketing, 73 (March), 14-37.

Vorhies, Douglas W. and Neil A. Morgan (2003), "A Configuration Theory Assessment of Marketing Organization Fit with Business Strategy and Its Relationship with Marketing Performance," Journal of Marketing, 67 (January), 100-15.

Wiesel, Thorsten, Bernd Skiera, and Julián Villanueva (2008), "Customer Equity: An Integral Part of Financial Reporting," Journal of Marketing, 72 (March), 1-14.

Woodside, Arch G. (2010), "Bridging the Chasm Between Survey and Case Study Research: Research Methods for Achieving Generalization, Accuracy, and Complexity," Industrial Marketing Management, 39 (1), 64-75.

(2013), "Moving Beyond Multiple Regression Analysis to Algorithms: Calling for Adoption of a Paradigm Shift from Symmetric to Asymmetric Thinking in Data Analysis and Crafting Theory," Journal of Business Research, 66 (4), 463-72. 